\title{
Modeling Investigation of Correlations between Elastic Properties Predicted by Rock Physics Model with Seismic Data (Case Study of an Iranian Oil Field)
}

\author{
Abolfazl Ezadi Sharif Abad, Ahmad Adib* \\ Department of Petroleum Engineering, Islamic Azad University, South Tehran Branch, Tehran, Iran \\ Email: abolfazlezadi.sh@gmail.com, *adib@azad.ac.ir
}

How to cite this paper: Abad, A.E.S. and Adib, A. (2018) Modeling Investigation of Correlations between Elastic Properties Predicted by Rock Physics Model with Seismic Data (Case Study of an Iranian Oil Field). Modeling and Numerical Simulation of Material Science, 8, 47-63.

https://doi.org/10.4236/mnsms.2018.83003

Received: June 13, 2018

Accepted: July 27, 2018

Published: July 30, 2018

Copyright $\odot 2018$ by authors and Scientific Research Publishing Inc. This work is licensed under the Creative Commons Attribution International License (CC BY 4.0).

http://creativecommons.org/licenses/by/4.0/

\begin{abstract}
Accurate characterization of seismic properties in the prediction of $\mathrm{P}$-wave and S-wave velocities through carbonate reservoirs is necessary due to their intrinsic heterogeneity. Moreover, both the waves velocities mentioned above are applied to the uncertainty analysis as well as the complexity investigation presented in the carbonate reservoirs. In this study, three wells of an Iranian oil field which its formation is the upper part of the Sarvak (Mishrif) has been studied. In accordance with the petrophysical interpretation of this oil field using Geo-log software, a rock physics model has been constructed based on Xu-Payne model (2009) using Hampson-Russel software to predict the elastic properties like P-wave and S-wave velocities as well as density. In the following, some synthetic seismic traces have been created based on the rock physics model using Hampson-Russel software to obtain the correlation coefficients of the seismic data with both the predicted and measured elastic properties. As results, the obtained correlation coefficients show that the predicted elastic properties by the rock physics model have higher quality than the measured elastic properties. In addition, the correlation coefficients of the predicted elastic properties in the well number 1, 2, and 3 have approximately increased by 19.6, 21.3, and 18.2 percent, respectively, in comparison to the correlation coefficients of the measured elastic properties. Therefore, the predicted elastic properties can be replaced with the low-quality measured elastic properties. Eventually, some templates have been created to accurate characterization the carbonate reservoir based on the rock physics model and also show the high-quality correlations between the rock physics model and the measured data.
\end{abstract}

\section{Keywords}

Carbonate Reservoir, Rock Physics Model, Elastic Property, Seismic Data 


\section{Introduction}

The correlation between data in the petroleum engineering is important because the data utilized in the petroleum science comes from the different resources such as well logging, seismography, and geology which each of them is obtained with different tools and scales. Therefore, the data validation seems necessary in order to increase the data accuracy. Also, the data validation can be achieved by applying the rock physics science [1].

The rock physics science can be applied to validate data, especially when there is no core data. Following the data validation, the elastic properties can be predicted utilizing the rock physics model. In the following, the rock physics templates are plotted to analyze of the reservoir [1].

The elastic properties predicted from the rock physics model have a higher quality than the measured elastic properties. Accordingly, these predicted elastic properties associated with a high-certainty can be applied to decrease the uncertainty of the reservoir investigation [1] [2].

Today, the methods of studying the elastic behavior of rock, including the rock physics method, have considerably improved and have remarkably been regarded by the oil companies to reduce the risk of the drilling operations. Now, the developed relationships of the rock physics method have been considered as a proper method for studying the elastic behavior of rock. This method has also been utilized to study the unknown dimensions of the petroleum engineering in the recent years [1] [2].

Remarkably, a carbonate reservoir has many problems in predicting the elastic properties like $\mathrm{P}$-wave and S-wave velocities as well as density due to its intrinsic heterogeneity. Additionally, this reservoir needs to predict accurately due to its complexity of the pores structure. Consequently, the rock physics method can accurately predict the elastic properties like the P-wave and S-wave velocities [1] [2].

Accordingly, the poorly measured data can be replaced with the predicted elastic properties as well as created the rock physics templates by defining a correct rock physics model from a carbonate reservoir [3] [4] [5] [6].

About the oil fields belong to the Persian Gulf basin, the upper part of the Sarvak formation is one of the most important oil formations of Iran and Arabian countries neighboring the Persian Gulf basins which is composed of shallow lime as well as shows a shallow sequence. Furthermore, the dissolution process during the burial cementation is the most important diagenesis process in the upper part of the Sarvak formation (Mishrif formation) [7].

The Persian Gulf is a shallow tectonic subsidence formed at the end of the Tertiary period in the southern part of the Zagros folding. However, its main trend was formed during the Pleistocene period and due to the Zagros folding. Further, this basin has an asymmetric structure that its slop and depth are much larger in Iran. Hence, the Persian Gulf line located along its length geologically divides it into two parts of the Arabic stable part in the south and the Iranian 
folded part. Figure 1 shows the geographical position of the upper part of the Sarvak formation in the Persian Gulf basin [7].

The case study of this research is an anticline field (Sirri field) located along a northeast-southwest axis. The eastern axis has more slope, as well. Also, the main faults of this field are parallel to the anticline axis. Furthermore, the dome-shaped origin of this field affected by the tectonic factors of the Cambrian salts. Moreover, the upper part of this field consists of the upper part of the Sarvak formation (Mishrif formation) which mainly consists of shallow carbonates. The studies applied on the Mishrif formation show that this formation consists of five faces:

1) Lower slope face,

2) Upper slope face,

3) Bioclastic Shoal face,

4) Lagoon face,

5) Rudist Biostrome and patch reef face.

Figure 2 and Figure 3 show the faces picture and the porosity-permeability distribution in the various faces of the Mishrif formation.

In the following, several researches that have been taken place in this research scope have been mentioned.

An integrated workflow was proposed to analyze the seismic petrophysics includes detailed petrologic characterization, incorporation of fundamental rock properties controls, rigorous petrophysical evaluation, and the use of a core calibrated rock physics model [8].

A synthetic models was constructed to illustrate why seismic petrophysics is

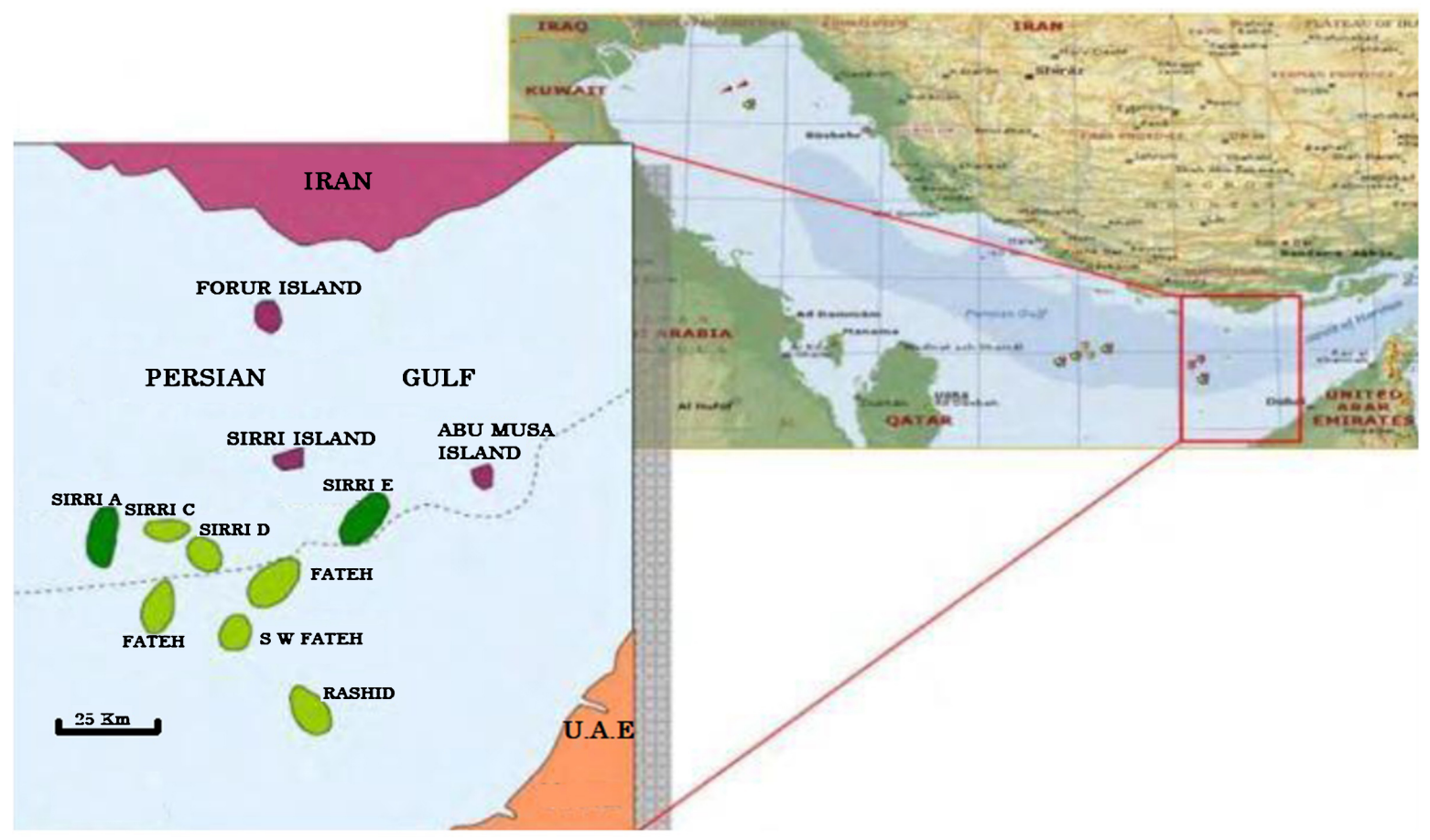

Figure 1. The geographical position of the upper part of the Sarvak formation in the Persian Gulf basin [7]. 

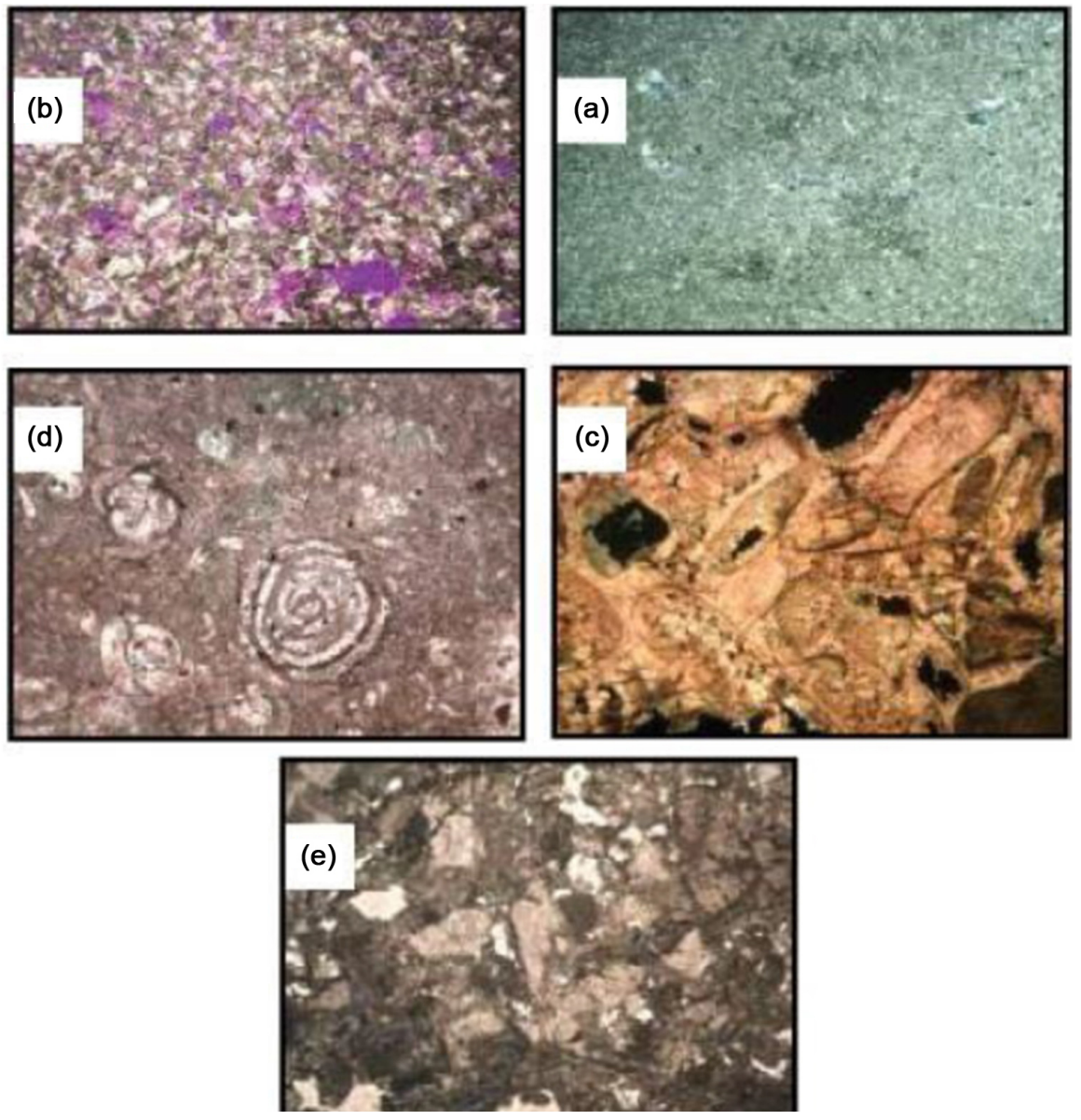

Figure 2. The faces picture of the Mishrif formation, (a) Lower slope face, (b) Upper slope face, (c) Bioclastic Shoal face, (d) Lagoon face, and (e) Rudist Biostrome and patch reef face [7].

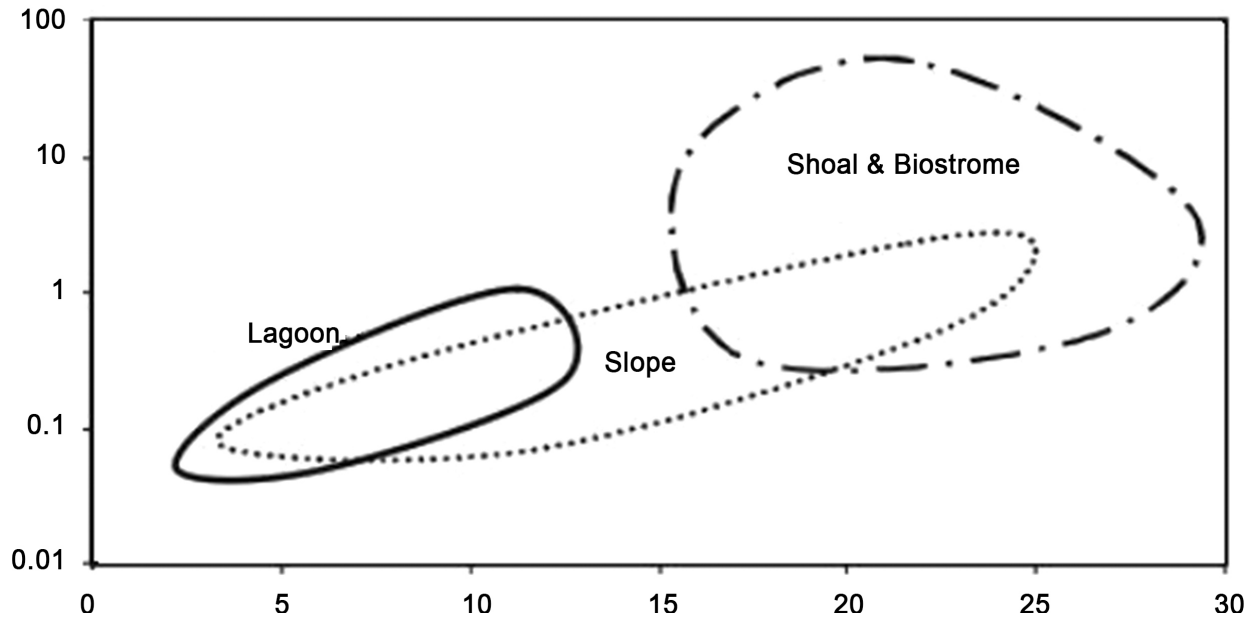

Figure 3. The porosity-permeability distribution in the various faces of the Mishrif formation [7].

so important as well as to show how carefully help the geoscientist can interpret acoustic and elastic impedance inversion from seismic data [9]. 
A classification system was developed for clastic rocks. Also, an accurate sound carbonate rock physics model is applied to account these system [10].

A direct analysis was occurred on the application of the log-data in the seismic analysis in the view of the stratigraphy, seismic petrophysics and shale anisotropy [11].

Three geophysical pore types (reference pores, stiff pores and cracks) were defined to represent the average elastic effective properties of complex pore structures [12].

A model was developed to predict the elastic parameters like the pseudo shear wave velocity and P-wave velocity using the petrophysical properties calculated from the logs [13].

In this research, at first a petrophysical interpretation of the Sirri oil field that is a carbonate oil field has been occurred. In the following, a rock physics model has been constructed to predict the elastic properties of this oil field. Finally, some synthetic seismic traces have been created based on the rock physics model to obtain the correlation coefficients of the seismic data with the predicted as well as the measured elastic properties of this oil field.

\section{Methodology}

In this part, the algorithm of the study is proposed by details. Figure 4 shows the algorithm of the study.

In the way that:

- In Precalc: the reservoir properties have been fed to the petrophysical model as Table 1.

- In Parameter Picking: the distribution ranges of the neutron, density, and gamma have been fed to the petrophysical model to calculate the porosity and lithology ranges.

- In petrophysical modeling: the probabilistic method (Multimin approach) has been applied in the Geo-log software to plot the log-plots porosity, water saturation, resistivity, and so on.

- In rock physics model construction: a rock physics model has been constructed in the Hampson-Russel software based on the Gosman (1951) method.

- In the elastic properties modeling: the clay-rich hydrocarbon carbonate method (RockSI module) has been applied in the Hampson-Russel software to predict the compressive-wave velocity ( $\mathrm{P}$-wave velocity), shear-wave velocity (S-wave velocity), and density.

- In synthesis seismic trace creation: the P-wave sonic resistance (P-wave velocity $\times$ density) has been obtained for the measured and the predicted P-wave velocity and then convolve with the use of the Ricker wavelet characterization as Table 2 in the Hampson-Russel software (Well module) to create the synthetic seismic trace of the elastic properties and comparison with the main trace of the wells seismography. 


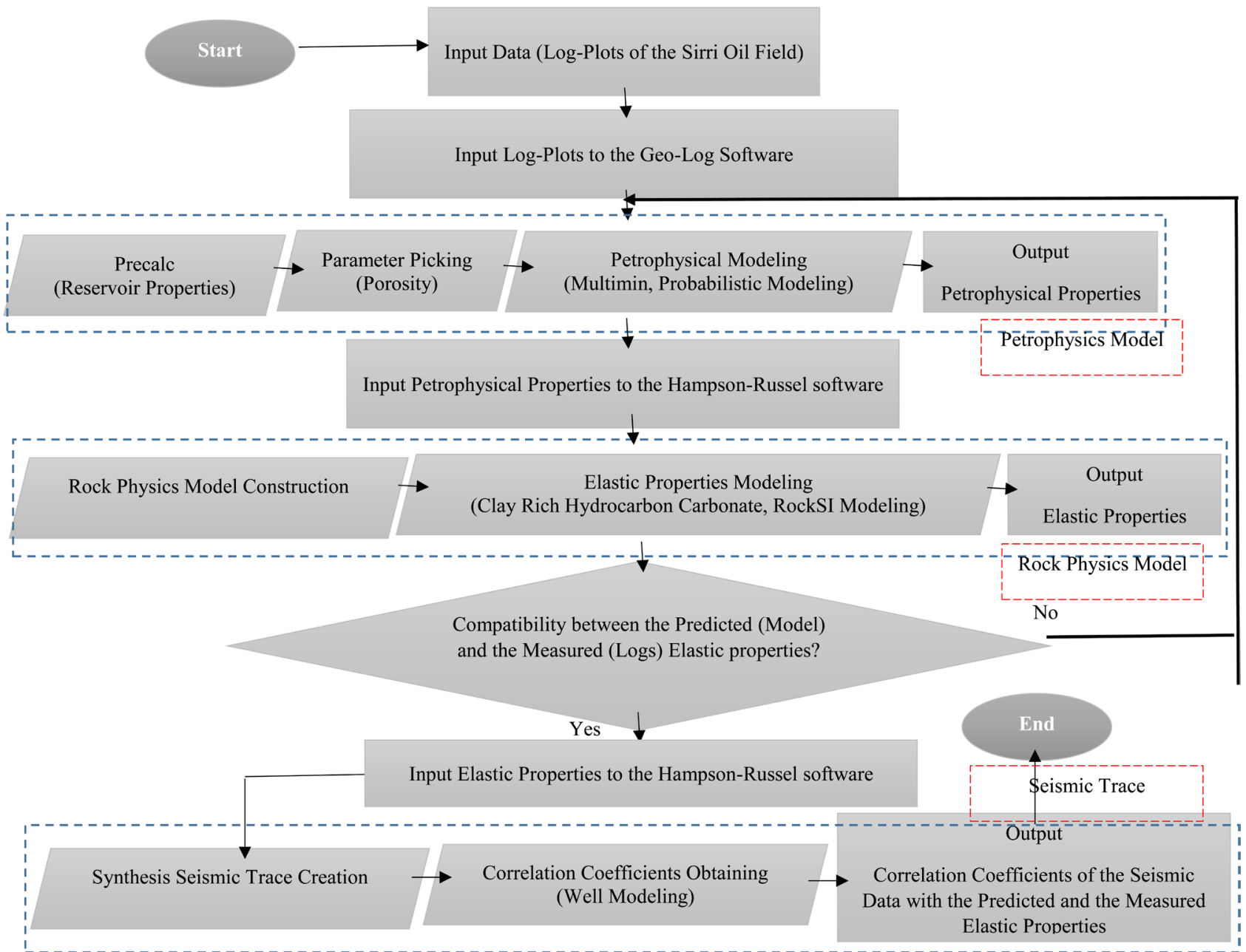

Figure 4. The algorithm of the study.

Table 1. The reservoir properties.

\begin{tabular}{ccccc}
\hline $\begin{array}{c}\text { Pressure } \\
(\mathrm{atm})\end{array}$ & Temperature $\left({ }^{\circ} \mathrm{C}\right)$ & Salinity $\left(\mathrm{gr} / \mathrm{cm}^{3}\right)$ & Oil Gravity $\left({ }^{\circ} \mathrm{API}\right)$ & Gas Specific Gravity (-) \\
\hline 74 & 100 & 0.13 & 33 & 0.66
\end{tabular}

Table 2. The Ricker wavelet characterization.

\begin{tabular}{cccc}
\hline Frequency (Hz) & Phase Rotation (degree) & Sample Rate (ms) & Wavelet Length (ms) \\
\hline 20 & 0 & 1 & 100 \\
\hline
\end{tabular}

\section{Results and Discussion}

At First, with the use of the neutron-density-gamma cross-plot of each well, the distribution range of the neutron-density-gamma for each well is introduced into the Geo-log software by the input window of the software. According to these cross-plots, the distribution ranges are between $0-20,5-25$, and $2.3-2.7$ for the gamma, neutron, and density, respectively, for all the wells. Accordingly, the lithology of the formation is carbonate type due to the distribution ranges of the 
data.

\subsection{Petrophysical Modeling}

In this part, the log-plot of each well contains the petrophysical properties like porosity, fluids saturation, and shale volume which are interpreted (modeled) with the use of the petrophysical modeling. Figures 5-7 show the log-plot of the interpreted petrophysical properties for the well \#1, well \#2, and Well \#3, respectively.

Each log-plot concludes the Ilam, Laffan, Mishrif (the case study of this research), and Khatiyah formations, respectively. Also, the labels of each log-plot from left to right contain the gamma-caliper-bit size log, the formations name and depth, the lithology log, the fluids type log, the water saturation log, the neutron-density-sonic velocity log, and the resistivity log, respectively. About the colors, the colors green, blue, cream, and gray are related to the oil-phase, the formation water-phase, the free water-phase, and the shale water-phase, respectively.

According to Figure 5, the caliper-bit size log shows a good strength of the well wall in terms of the wellbore stability as well as the clay swelling, and also the quality of the logs taken (especially the density log) for the well \#1. Additionally, the gamma and lithology logs show low volume of the shale in the Mishrif formation and high volume of the shale in the Laffan formation and some parts of Khatiyah formation for the well \#1. Moreover, the lithology log shows that the lithology of the Mishrif formation is carbonate (calcite) for the well \#1. In the following, the fluid type log as well as the separation of the deep and shallow resistivity logs show high volume of hydrocarbon in the Mishrif formation in comparison to the others formations for the well \#1. Furthermore, the water saturation log shows high water saturation in the Mishrif formation in comparison to the others formations for the well \#1. Finally, the adaptation of the neutron and density logs shows high purity of calcite for the well \#1.

Remarkably, the maximum porosity is approximately $25 \%$ (the exact quantity hasn't be reported because of the errors of the log-tools) based on the porosity $\log$ and the minimum shale volume is lower than $3 \%$ based on the lithology log for well \#1.

According to Figure 6, the different logs show the similar characteristics for the well \#2 in comparison to the well \#1. However, there is a few differences such as water saturation in the water saturation log for the well $\# 2$ in comparison to the well \#1.

Also, the maximum porosity is approximately $25 \%$ based on the porosity log and the minimum shale volume is approximately $3 \%$ based on the lithology log for the well \#2.

According to Figure 7, the different logs show the similar characteristics for the well \#3 in comparison to the wells \#1 and \#2, as well. However, there is a few differences such as water saturation in the water saturation log for the well \# 3 in 


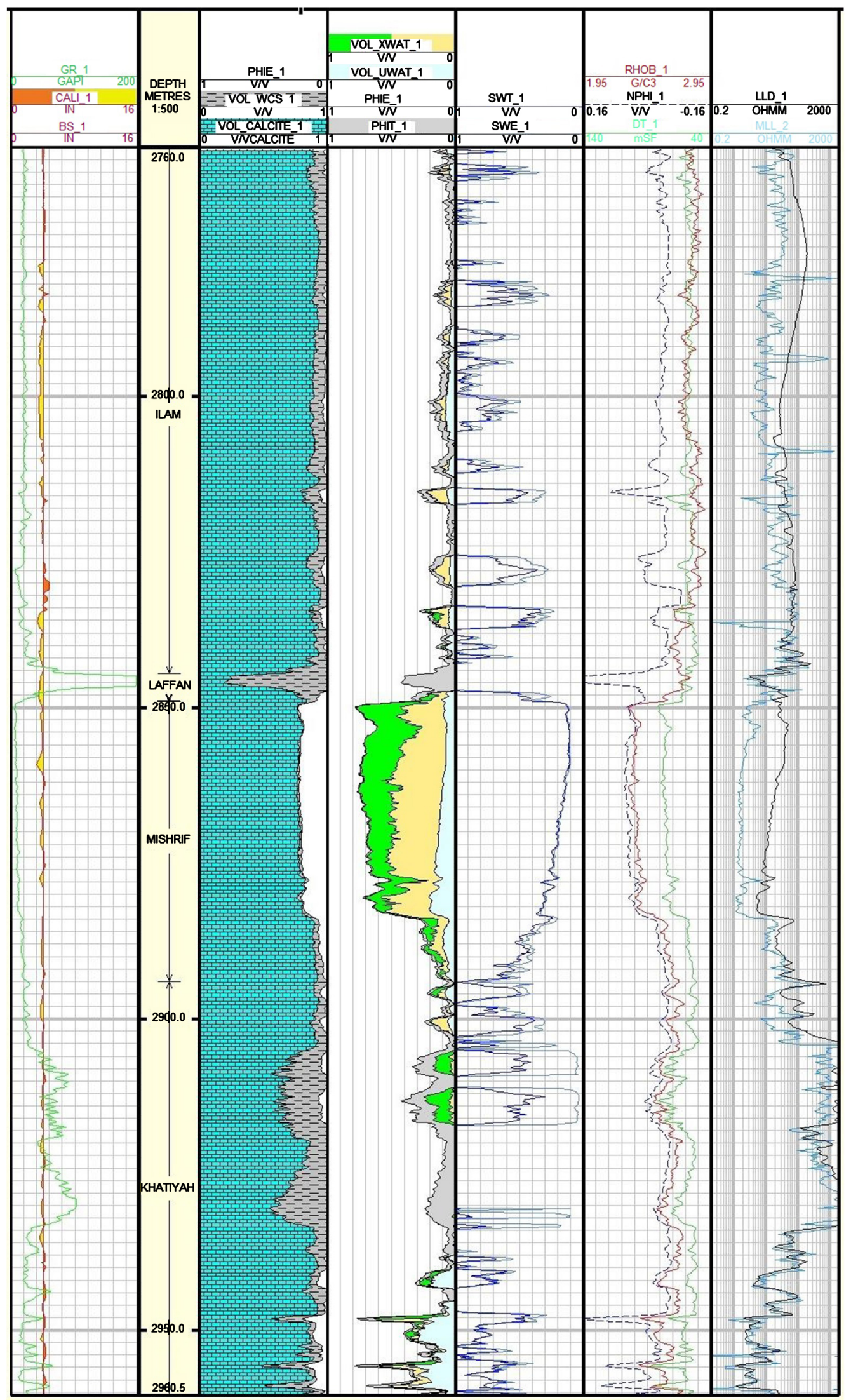

Figure 5. The log-plot of the interpreted petrophysical properties for the well \#1. 
A. E. S. Abad, A. Adib

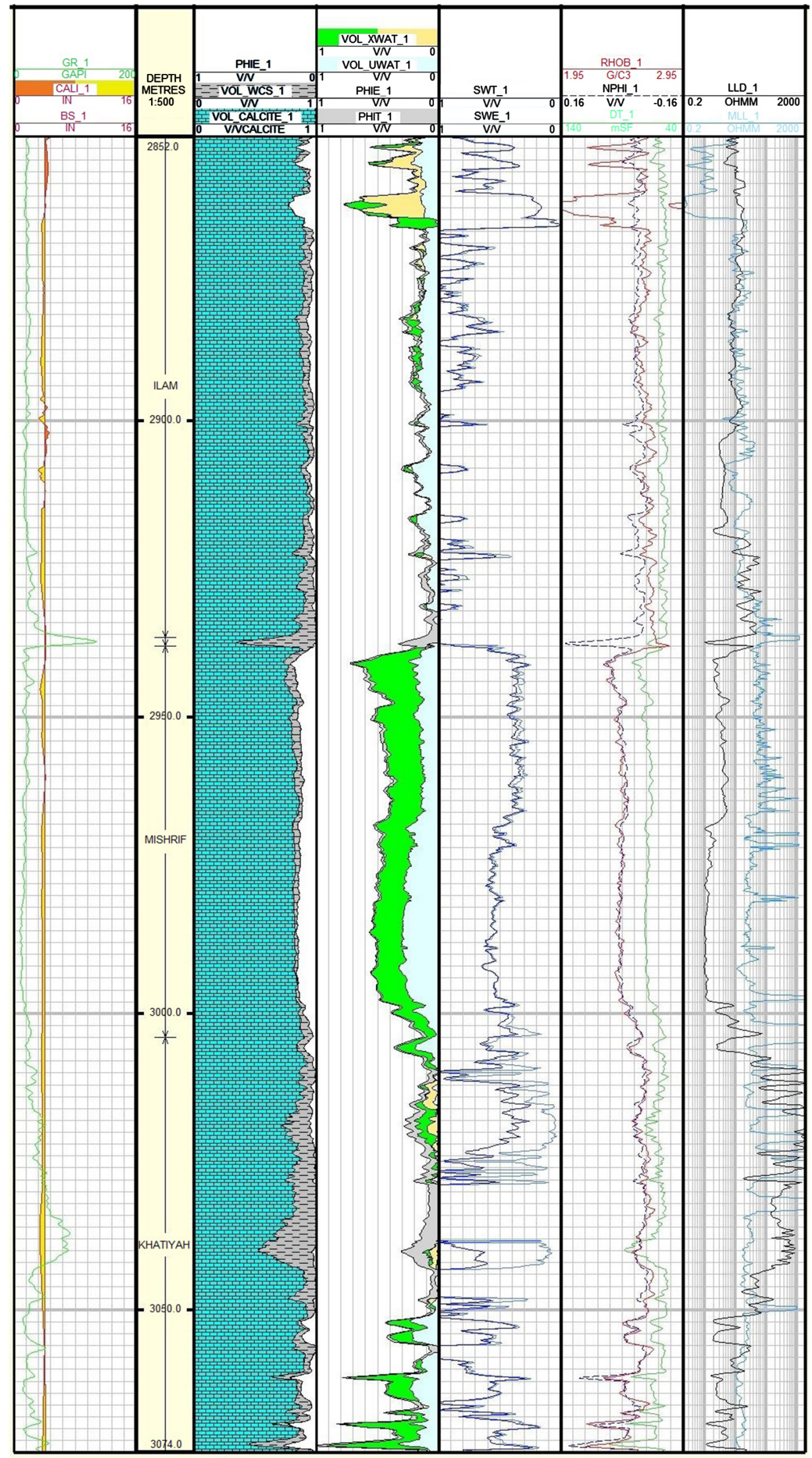

Figure 6. The log-plot of the interpreted petrophysical properties for the well \#2. 


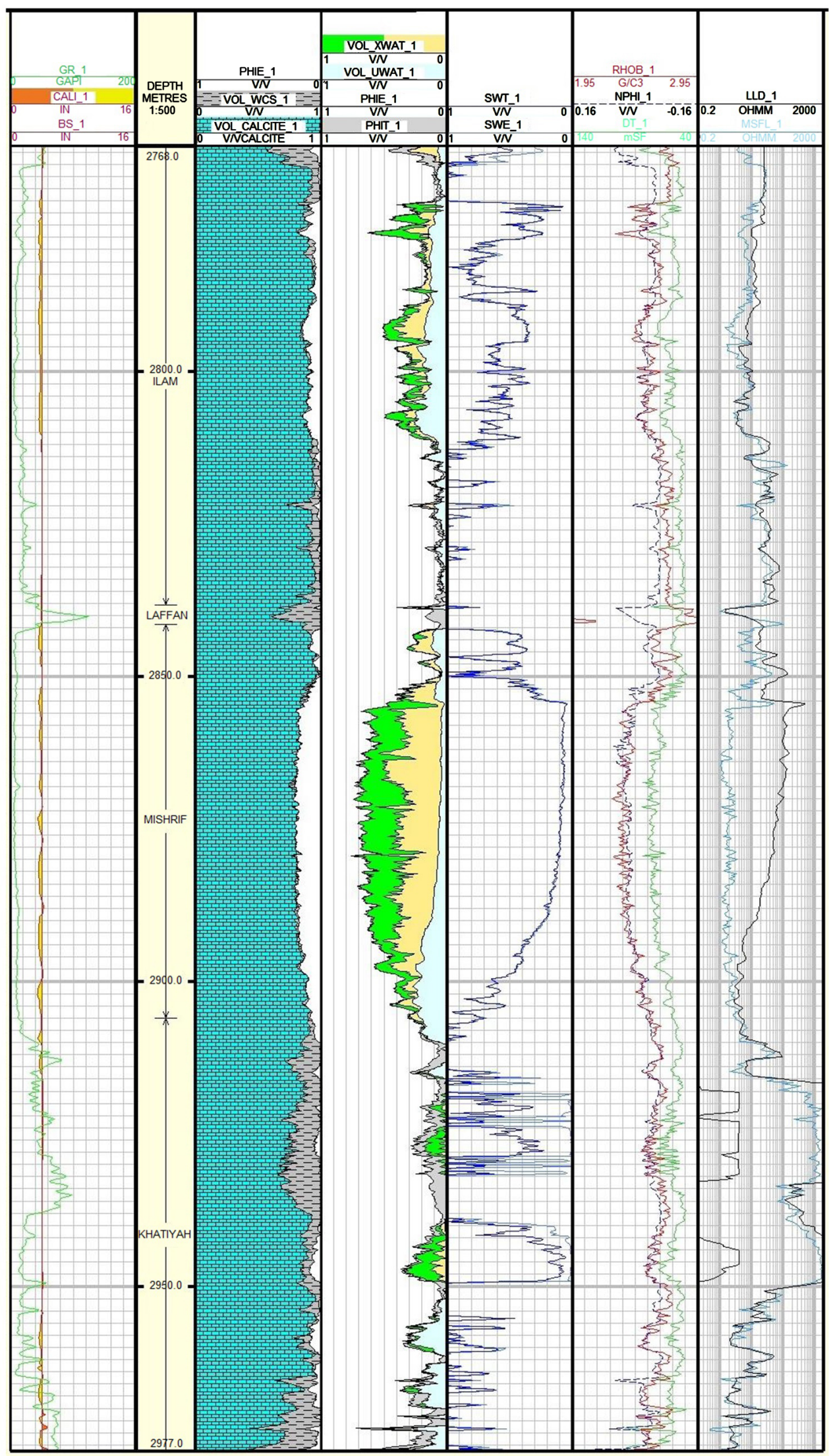

Figure 7. The log-plot of the interpreted petrophysical properties for the well \#3. 
comparison to the wells \#1 and \#2, as well.

Also, the maximum porosity is approximately $25 \%$ based on the porosity log and the minimum shale volume is lower than $3 \%$ based on the lithology log for the well \#3.

\subsection{Rock Physics Modeling}

In this part, the plot of each well contains the elastic properties like P-wave velocity, S-wave velocity, and density which are predicted (modeled) with the use of the rock physics modeling. Figures 8-10 show the plot of the predicted elastic properties for the well \#1, well \#2, and Well \#3, respectively.

Each plot concludes the Laffan, Mishrif (the case study of this research), and

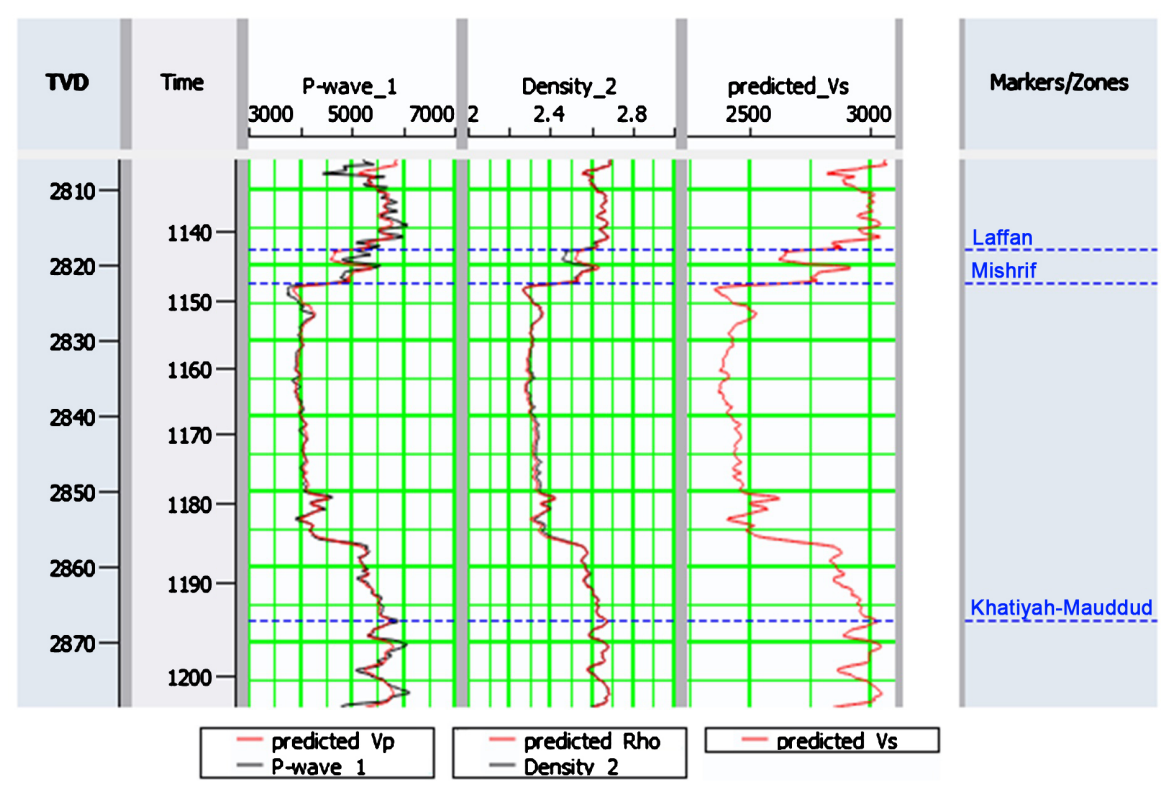

Figure 8. The plot of the predicted elastic properties for the well \#1.

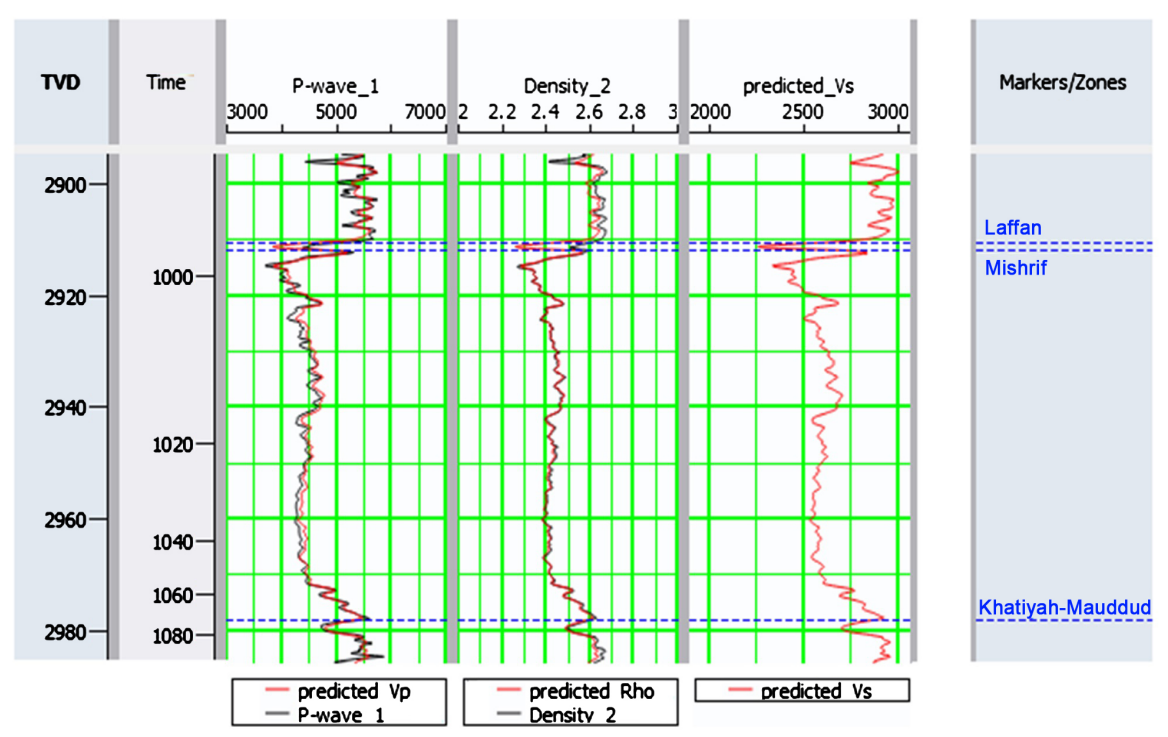

Figure 9. The plot of the predicted elastic properties for the well \#2. 


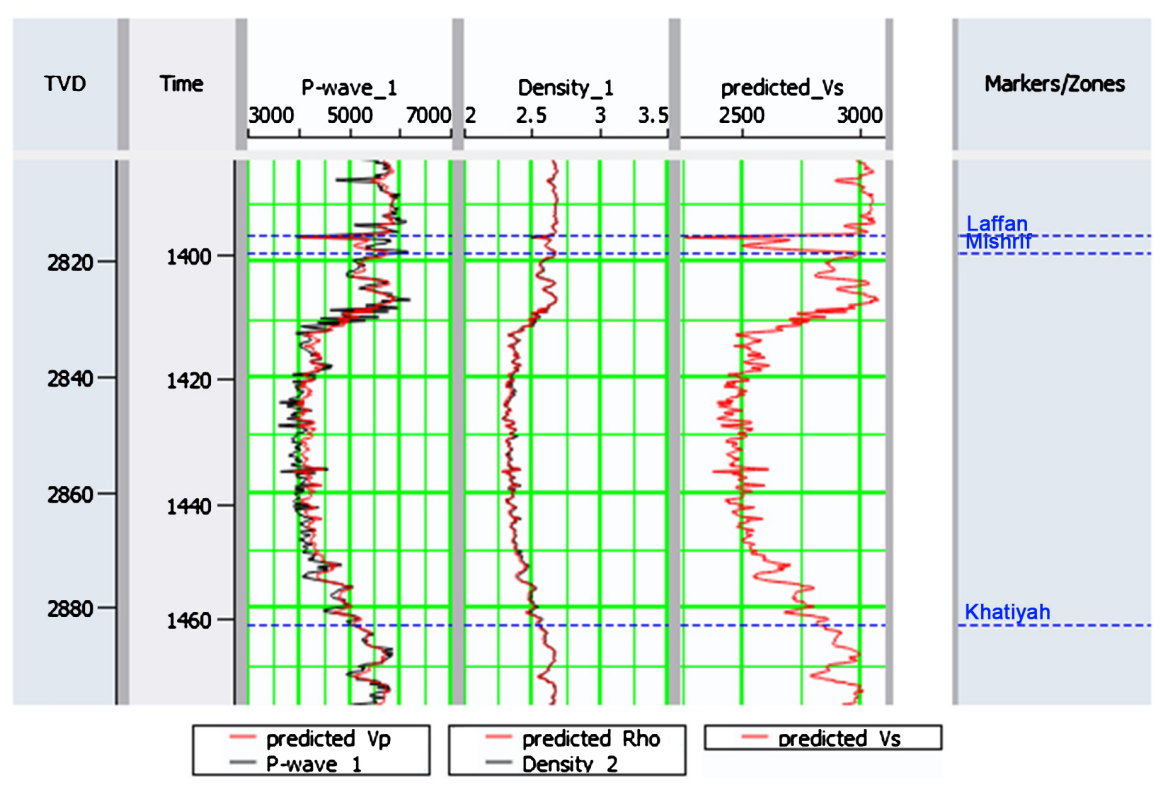

Figure 10. The plot of the predicted elastic properties for the well \#3.

Khatiyah formations, respectively. Also, the labels of each plot from left to right contain the true vertical depth, time, P-wave velocity, density, S-wave velocity, and formation zone, respectively. About the colors, the colors red and black are related to the predicted and the measured elastic properties, as well. However, the red plot only exists in the fifth column of each plot because S-wave velocity hasn't been measured before by the log-plots for the field.

According to Figures 8-10, there are the good compatibilities between the predicted elastic properties by the rock physics model and the measured elastic properties by the log-plots. Accordingly, the qualities of both the rock physics model and measuring tools were high enough and also didn't exist any errors in the prediction and measuring the elastic properties.

\subsection{Seismography Technique}

After obtaining the maximum compatibilities between the predicted and the measured elastic properties, the correlation coefficients of the seismic data with the measured and the predicted elastic properties have been obtained.

In this part, the plot of each well contains the main trace of the well seismography and the synthesis seismic trace of the elastic properties which are obtained with the use of the seismography technique.

Figure 11 shows the comparison between the main trace of the well seismography and the synthesis seismic trace of the measured elastic properties for the well \#1, well \#2, and well \#3. Also, Figure 12 shows the comparison between the main trace of the well seismography and the synthesis seismic trace of the predicted elastic properties for the well \#1, well \#2, and well \#3.

Each plot concludes the Ilam, Laffan, Mishrif (the case study of this research), Khatiyah, and Kazhdumi formations, respectively. Also, the labels of each log-plot from left to right contain the time, formation top, trace, common depth 

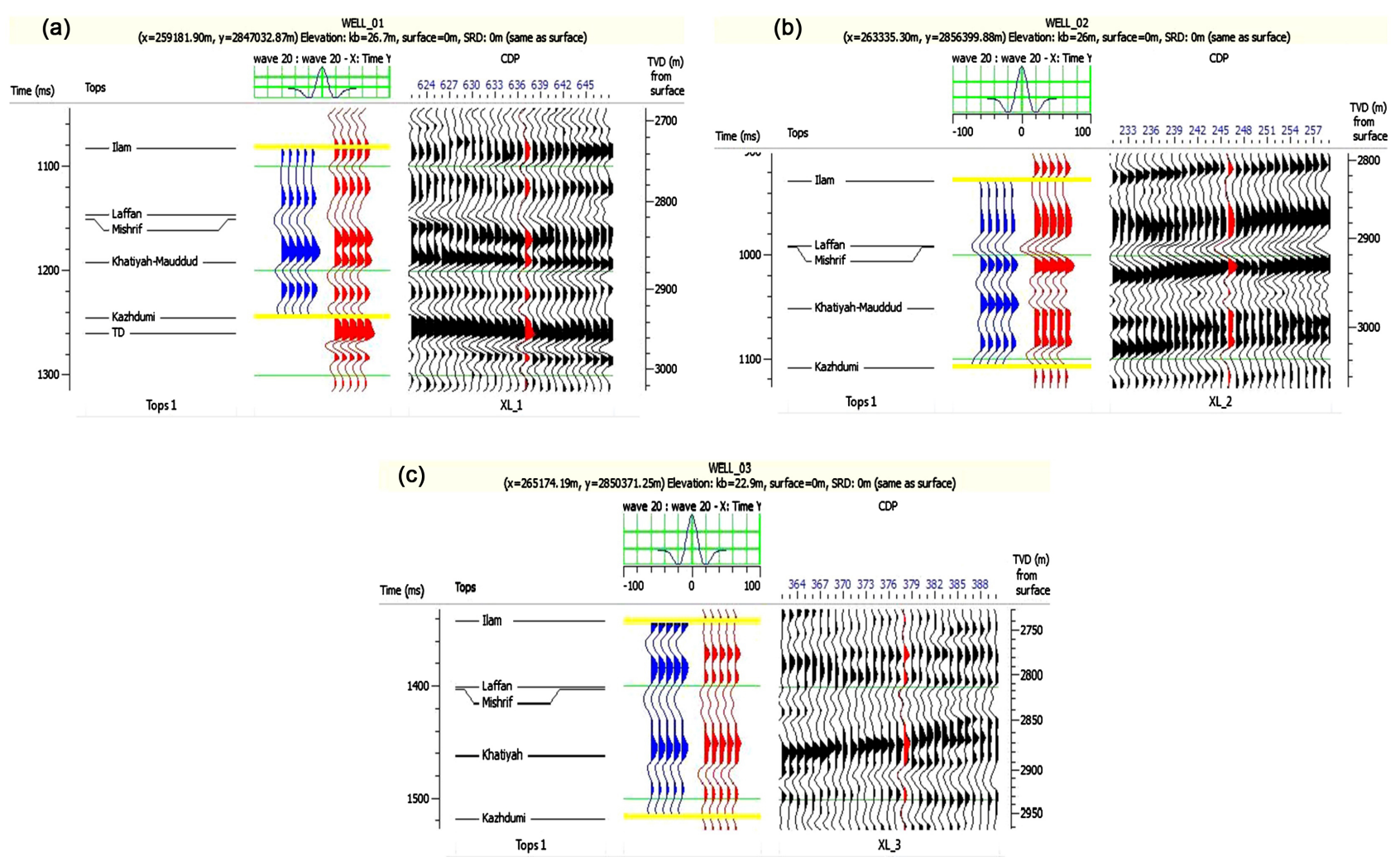

Figure 11. The comparison between the main trace of the well seismography and the synthesis seismic trace of the measured elastic properties for the (a) well \#1, (b) well \#2, and (c) well \#3.

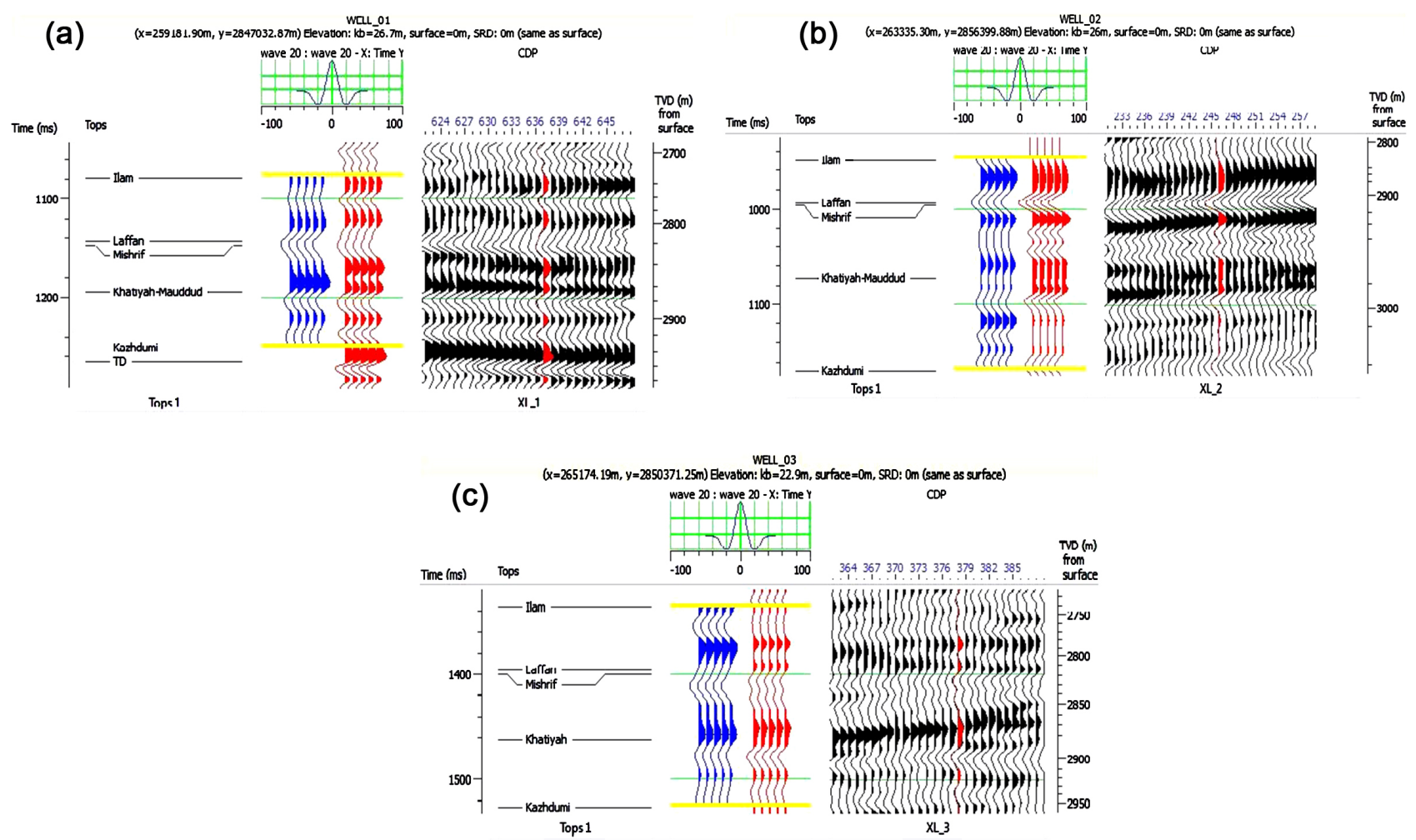

Figure 12. The comparison between the main trace of the well seismography and the synthesis seismic trace of the predicted elastic properties for the (a) well \#1, (b) well \#2, and (c) well \#3. 
pint, and true vertical depth, respectively. About the colors, the colors red and blue are related to the main trace of the well seismography and synthetic seismic trace, as well. However, the main trace of the well seismography can be obtained from the trace of the field seismography shown by the black color.

According to Figure 11, there are the good similarities (60-80\% similarities) between the seismic data and the measured data based on the peaks as well as the troughs of the graphs. According to Figure 12, there are the very good similarities ( $80 \%-100 \%$ similarities) between the seismic data and the predicted data for the wells, as well. Therefore, the similarities between the seismic data and the predicted data are higher than the similarities between the seismic data and the measured data for the wells. Based on this similarities, the correlation coefficients of the seismic data with the measured and the predicted data have been obtained for the wells. Table 3 shows the correlation coefficients of the seismic data with the measured and the predicted elastic properties for the wells.

Increasing the correlation coefficients of the seismic data with the predicted elastic properties in comparison with the correlation coefficients of the seismic data with the measured elastic properties shows the better qualities of the predicted elastic properties than the measured elastic properties.

\subsection{Rock Physics Templates}

In a rock physics template, an elastic property is plotted versus a reservoir property in order to the comparison between the elastic property predicted by the rock physics model and the reservoir property measured by the petrophysical model based on the data quantities as well as the data distributions at each point (grid) of the reservoir. Therefore, a rock template can characterize hydrocarbon reservoirs. Accordingly, a rock physics template is so important because of the reservoir heterogeneity in carbonate reservoirs. In this study, the graph P-wave velocity versus the porosity is plotted and considered as the rock physics template. Also, the shale volume is considered as the third property altered in the graph because the porosity as well as the shale volume extremely effect on $\mathrm{P}$-wave velocity in carbonate reservoirs.

Figure 13 shows the rock physics template of P-wave velocity, porosity, and shale volume for the wells.

According to Figure 13, the main porosity of the reservoir is located around the porosity 0.05 and 0.2 . Based on this range of porosity, and according to the

Table 3. The correlation coefficients of the seismic data with the measured and the predicted elastic properties for the wells.

\begin{tabular}{cccc}
\hline Well No. & \#1 & $\# 2$ & \#3 \\
Correlation Coefficient (\%) & & 60.60 & 58.8 \\
\hline Seismic Data vs. Measured Data & 60.90 & 82.20 & 77.00 \\
Seismic Data vs. Predicted Data & 80.20 & 21.60 & 18.2 \\
Difference & 19.30 &
\end{tabular}




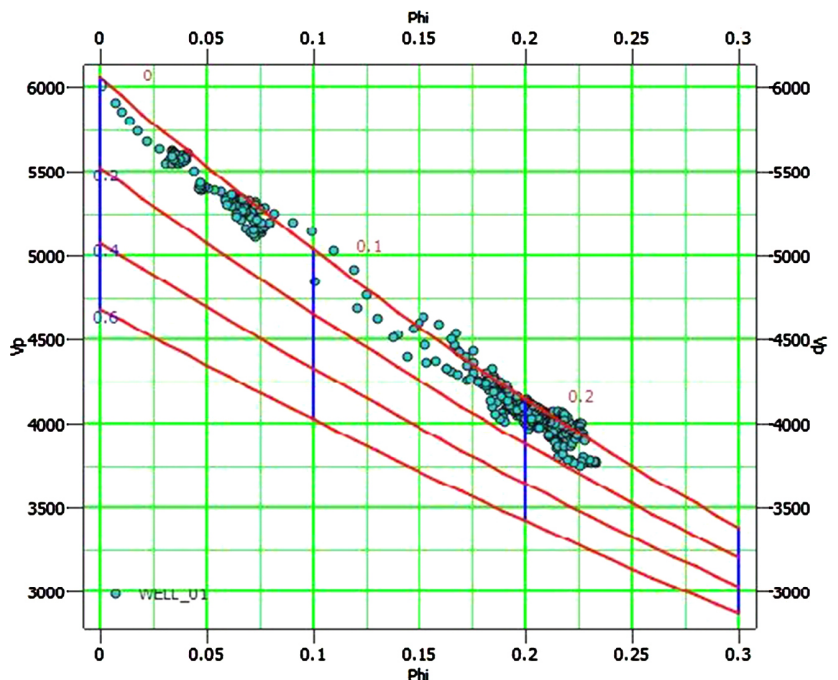

(a)

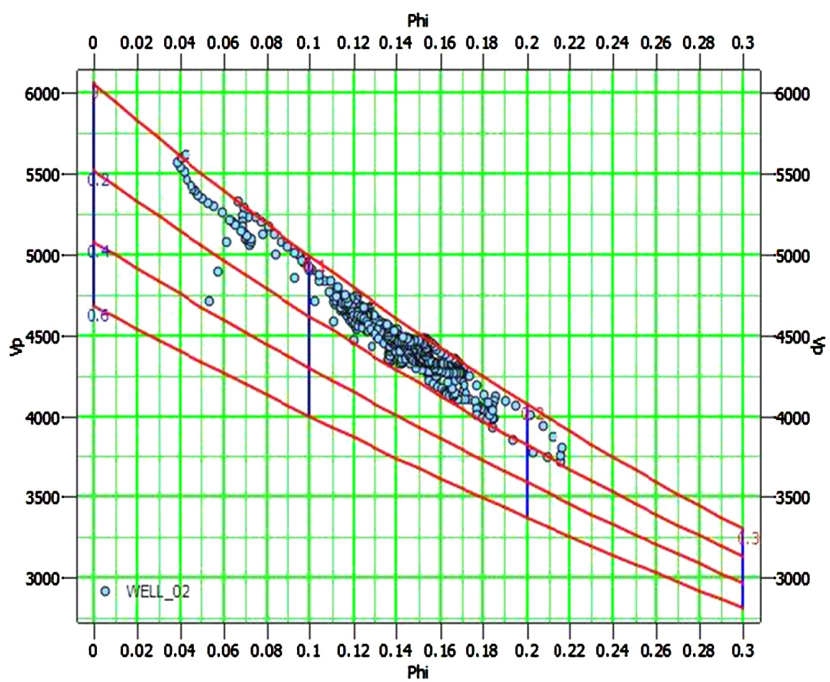

(b)

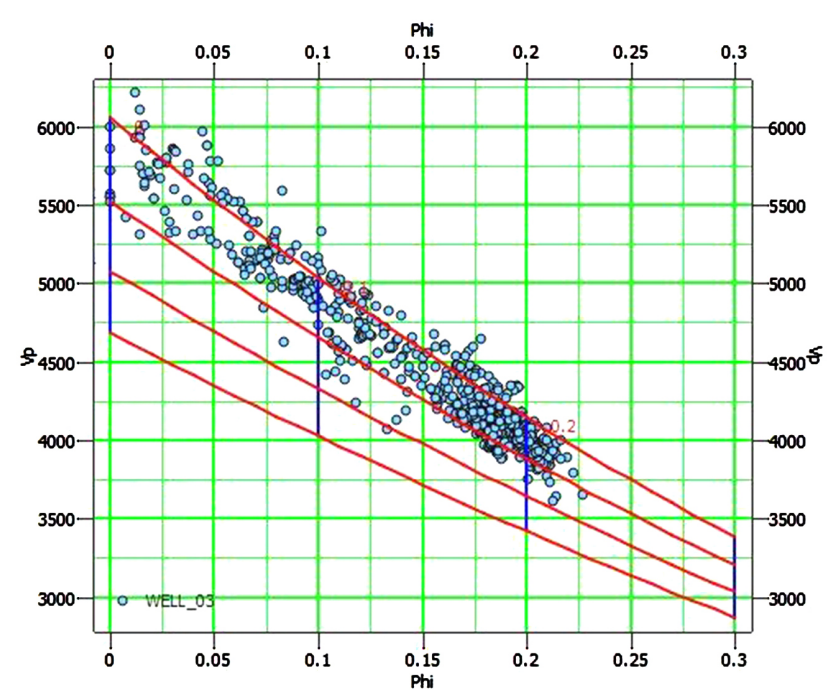

(c)

Figure 13. The rock physics template of P-wave velocity, porosity, and shale volume for the (a) well \#1, (b) well \#2, and (c) well \#3.

Zhao et al. (2013) classification about the main process in a carbonate reservoir, the main process in this reservoir is dolomization. And given that the reservoir is calcite type, the template correctly characterize the reservoir. Also, the data of the wells \#1 and \#2 changes in a known trend and the data distributes in the specific points (grids) of the reservoir despite the well \#3 (specific the porosity range less than 5 percent). Therefore, this indicates a poor quality of the data of the well \#3 in comparison to the data of the wells \#1 and \#2. This can be due to the heterogeneity of the formation in the region of the well \#3 and inability of the tools to measure the data. In the following, applying the high-accurate and more-sensitive tools can solve the problems.

\section{Conclusions}

Based on the aspect ratios of the pores obtained from the variable parameters of 
the rock physics model, the major porosity of the reservoir was $0.22,0.05$, and 0.01 , respectively, for the wells \#1, \#2, and \#3.

Based on the inter-porosity of the shale and the aspect ratios of the pores obtained from the variable parameters of the rock physics model as well as the use of the manual guide of the Hampson-Russel software, the clay minerals of the reservoir were the kaolinite type.

Also, the elastic properties of the reservoir were predicted by the rock physics model that had good compatibilities with the elastic properties measured by the log-plots. Therefore, this confirms the performance as well as the validity of the rock physics model.

Moreover, the shear-wave velocity of the reservoir was predicted by the rock physics model that was not measured by the log-plots.

In addition, the correlation coefficients of the seismic data with the measured elastic properties were obtained for the wells \#1, \#2, and \#3 as $60.9 \%, 60.6 \%$, and $58.8 \%$, respectively.

However, the correlation coefficients of the seismic data with the predicted elastic properties were obtained for the wells \#1, \#2, and \#3 as $80.2 \%, 82.2 \%$, and $77 \%$, respectively.

In accordance with the correlation coefficients, the correlation coefficients of the seismic data with the predicted elastic properties were higher than the correlation coefficients of the seismic data with the measured elastic properties. Therefore, this indicates the better qualities and accuracies of the predicted elastic properties by the rock physic model than the measured elastic properties by the log-plot.

Based on the correlation coefficients, the rock physics model alone has a high performance and accuracy in the prediction of the elastic properties. However, the use of the rock physics model is very useful when the data measured from the log-plots is not high-quality for reasons such as the sensitivity of the log tools or the data is unmeasurable.

Also, the rock physic modeling is an easy-to-use and low-cost way to apply validation of the measured data.

Finally, the rock physics template obtained from the rock physics model can characterize the reservoir and also indicates the data quantities and distributions of the model.

\section{Acknowledgements}

The authors are grateful to the Islamic Azad University, South Tehran Branch, for supporting this research.

\section{Conflicts of Interest}

The authors declare no conflicts of interest regarding the publication of this paper.

\section{References}

[1] Mavko, G., Mukerji, T. and Dvorkin, J. (2009) The Rock Physics Handbook: Tools 
for Seismic Analysis of Porous Media. Cambridge University Press, Cambridge. https://doi.org/10.1017/CBO9780511626753

[2] Avseth, P., Mukerji, T. and Mavko, G. (2010) Quantitative Seismic Interpretation: Applying Rock Physics Tools to Reduce Interpretation Risk. Cambridge University Press, Cambridge.

[3] Bosch, M., Mukerji, T. and Gonzalez, E.F. (2010) Seismic Inversion for Reservoir Properties Combining Statistical Rock Physics and Geostatistics: A Review. Geophysics, 75, A165-A176. https://doi.org/10.1190/1.3478209

[4] Avseth, P., Mukerji, T., Mavko, G. and Dvorkin, J. (2010) Rock-Physics Diagnostics of Depositional Texture, Diagenetic Alterations, and Reservoir Heterogeneity in High-Porosity Siliciclastic Sediments and Rocks-A Review of Selected Models and Suggested Work Flows. Geophysics, 75, A31-A47.

https://doi.org/10.1190/1.3483770

[5] Vernik, L. and Milovac, J. (2011) Rock Physics of Organic Shales. The Leading Edge, 30, 318-323. https://doi.org/10.1190/1.3567263

[6] Andrä, H., Combaret, N., Dvorkin, J., Glatt, E., Han, J., Kabel, M. and Marsh, M. (2013) Digital Rock Physics Benchmarks-Part I: Imaging and Segmentation. Computers \& Geosciences, 50, 25-32. https://doi.org/10.1016/j.cageo.2012.09.005

[7] Al-Zaabi, M.R., Taher, A.K., Azzam, I.N. and Witte, J. (2010) Geological Overview of the Middle Cretaceous Mishrif Formation in Abu Dhabi. Abu Dhabi International Petroleum Exhibition and Conference. Society of Petroleum Engineers. https://doi.org/10.2118/137894-MS

[8] Kittridge, M.G., Taylor, T.R., Braunsdorf, N.R., Hathon, L.A. and Bryndzia, L.T. (2004) Seismic Petrophysics for Clean Sandstones: Integrated Interrogation of Laband Well-Based Data for Improved Rock Physics Modeling. SEG Technical Program Expanded Abstracts, Society of Exploration Geophysicists, 1750-1753. https://doi.org/10.1190/1.1845164

[9] Walls, J., Dvorkin, J. and Carr, M. (2004) Well Logs and Rock Physics in Seismic Reservoir Characterization. Offshore Technology Conference. https://doi.org/10.4043/16921-MS

[10] Xu, S. and Payne, M.A. (2009) Modeling Elastic Properties in Carbonate Rocks. The Leading Edge, 28, 66-74. https://doi.org/10.1190/1.3064148

[11] Smith, T.M. (2011) Practical Seismic Petrophysics: The Effective Use of Log Data for Seismic Analysis. The Leading Edge, 30, 1128-1141. https://doi.org/10.1190/1.3657071

[12] Zhao, L., Nasser, M. and Han, D.H. (2013) Quantitative Geophysical Pore-Type Characterization and Its Geological Implication in Carbonate Reservoirs. Geophysical Prospecting, 61, 827-841. https://doi.org/10.1111/1365-2478.12043

[13] Abe, S.J., Olowokere, M.T. and Enikanselu, P.A. (2018) Development of Model for Predicting Elastic Parameters in "Bright" Field, Niger Delta Using Rock Physics Analysis. NRIAG Journal of Astronomy and Geophysics. 